\title{
Ensuring the High Performance of Design and Engineering Firms in Mexico's Aerospace Industry: A Qualitative Comparative Analysis
}

\author{
María Aline Manzo ${ }^{1}$, José Carlos Rodríguez ${ }^{2 *}$ \\ ${ }^{1}$ Universidad Vasco de Quiroga, Facultad de Negocios, Morelia, 58090, Mexico \\ ${ }^{2}$ Universidad Michoacana de San Nicolás de Hidalgo, Instituto de Investigaciones Económicas y \\ Empresariales, Ciudad Universitaria, Morelia, 58004, Mexico
}

\begin{abstract}
The aerospace industry is considered strategic for economic and national security reasons because it generates short- and long-term benefits for countries, such as new investments, technology transfers, and spillover. Therefore, this research aimed to identify the necessary and sufficient conditions for guaranteeing the high performance of design and engineering firms (DEFs) in Mexico's aerospace industry. Taking a resource-based perspective enhanced by absorptive capacity and entrepreneurship approaches, this study contributes to understanding the causal ambiguity and social complexity characterizing the relationship between firms' performance and resource allocation. Additionally, this research used a fuzzy-set qualitative comparative analysis (fsQCA) method to gain insight into the configurations (i.e., sets of resources) that lead firms to achieve high performance levels (HPLs) in Mexico's aerospace industry. The results demonstrated that absorptive capacity, innovation capacity, entrepreneurial capacity, research and development activities, and specialized human resources are necessary conditions for achieving HPLs.
\end{abstract}

Keywords: Aerospace industry; Design and engineering firms; fsQCA; High performance levels; Mexico

\section{Introduction}

France, Germany, the United Kingdom, and the United States are global leaders in the aerospace industry. Nevertheless, new players (including research, production, and manufacturing centers) have recently emerged in Brazil, China, India, Mexico, and Singapore, lowering production costs for aircraft components and other mechanical and electronic systems through intercompany collaboration (Bédier et al., 2008; Casalet, 2013). Emerging economies aim to pursue innovation and disseminate new knowledge to reduce the technological gap between themselves and industrialized economies (Fu et al., 2011). Overall, the aerospace industry in emerging economies has focused on developing joint venture projects between foreign and local investors and other stakeholders to fulfill original equipment manufacturers' (OEMs') requirements (Bédier et al., 2008; Casalet, 2013; Deloitte, 2019).

In this regard, Mexico has engaged in successful collaboration and implemented strategic actions, such as export promotion and research and development (R\&D) efforts, to develop joint ventures, which, combined with the government's promotion of technology

${ }^{*}$ Corresponding author's email: jcrodriguez@umich.mx, Tel.: +52 (443) 179-6976 doi: 10.14716/ijtech.v13i1.4861 
transfer, have led to the growth of the country's aerospace industry (Goldstein, 2002; Goldstein, 2006; Flores and Villareal, 2017). In fact, Mexico is considered one of the most important investment locations in the aerospace industry and an example of a consolidated aerospace industry that aims to boost innovation (ProMéxico, 2016; Flores and Villareal, 2017). Typically, design and engineering firms (DEFs) have driven the aerospace industry in Mexico, and their performance relies heavily on creating and disseminating new knowledge and venturing into different innovative areas within firms to expand their client portfolios with new products, services, and technologies (FEMIA, 2015).

From a theoretical perspective, the resource-based view considers causal ambiguity and social complexity as two essential features for understanding and explaining firms' performance (Barney and Clark, 2007). Qualitative comparative analysis (QCA) deals with causal complexity by analyzing configurations (i.e., sets of resources) resulting from combinations of different conditions (i.e., resource allocations; Ragin, 2008; Mello, 2021). This paper argues that the causal ambiguity and social complexity considered by the resource-based view can be analyzed using QCA methods to investigate complex causal processes (Wagemann, 2012; Parente and Federo, 2019; Gerrits and Pagliarin, 2020). QCA approaches explain how the presence or absence of different conditions in alternative configurations can result in similar outputs (Ragin, 2008). The set-theoretic relations in QCA employ the concepts of equifinal, conjunctural, and asymmetric causation as explanations for causal complexity (Wagemann, 2012), which in this research related to Mexico's aerospace industry. The research question underpinning this study was as follows: What are the necessary and sufficient conditions that lead DEFs in Mexico's aerospace industry to achieve high performance levels (HPLs)?

The results suggest that five conditions are necessary for DEFs in Mexico's aerospace industry to achieve HPLs: R\&D activities, entrepreneurial capacity (EC), absorptive capacity (AC), innovation capacity (IC), and specialized human resources (SHR). The results also suggest that R\&D and EC are crucial for achieving HPLs, while AC, IC, and SHR are peripheral to the desired outcome. Finally, this study identified some configurations leading to HPLs in DEFs in Mexico's aerospace industry. In this country, small- and medium-sized companies share risk through alliances and joint research projects, mainly supported by the National Council for Science and Technology (CONACYT). The results suggest that DEFs can develop firm-level strategies for managing the resources and processes underpinning the R\&D activities, entrepreneurship, and innovation that will lead to high-performing DEFs in Mexico's aerospace industry.

Besides this introduction, the paper is organized into four sections. Section 2 presents the literature review that supported the study. Section 3 discusses the fuzzy-set qualitative comparative analysis (fsQCA) model employed in the research for data collection, case selection, and analysis. Section 4 evaluates and discusses the empirical results, and Section 5 presents concluding remarks.

\section{Literature Review}

\subsection{Firms' Performance and Strategic Management}

The resource-based view uses the concepts of causal ambiguity and social complexity to explain why some firms outperform others. The approach is based on two fundamental assumptions (Barney and Clark, 2007; Barca, 2017): First, resources are heterogeneously distributed among firms, and second, resources are imperfectly mobile between firms and industries. Thus, resources are seen as valuable, rare, non-imitable, and non-substitutable, resulting in quantity and quality differences across resource allocations but essential for developing and sustaining competitive advantage (Barney and Clark, 2007; Newbert, 2007; 
Barca, 2017).

Additionally, the AC model explains how firms can achieve superior performance by applying and assimilating new knowledge through a learning process (Cohen and Levinthal, 1989; 1990). In this model, AC's intangible, idiosyncratic, and cumulative nature makes it difficult to imitate, since converting knowledge is the basis for superior performance (Moon, 1999). In this research, IC and R\&D were necessary conditions for DEFs to achieve superior performance (i.e., HPLs) in Mexico's aerospace industry since innovation is a fundamental source of success and survival for firms in a complex environment. Indeed, R\&D influences IC, given that both activities feed a firm's internal innovation process and competitive advantage (Fosfuri and Tribó, 2008).

Finally, entrepreneurship is another condition that leads firms to achieve superior performance through the process of discovering and creating business opportunities. In this study, EC allowed for the identification and creation of profitable opportunities for firms requiring access to information and knowledge and the ability to recognize, perceive, and develop economically viable projects (Heru, 2016; Koroleva et al., 2020). The entrepreneurial approach highlights the importance of knowledge, technical ability, experience, and continuous training as sources of the valuable, rare, non-imitable, and nonsubstitutable SHR necessary for developing superior performance.

\subsection{The Aerospace Industry in Mexico}

Aerospace research, production, and manufacturing centers have arisen in several emerging economies in recent decades, leading to these economies being positioned in a competitive way in the global aerospace industry for several reasons. In the case of Mexico, although this industry only started developing a few decades ago, it achieved significant importance in 2004 since specialized foreign direct investment in the aerospace industry arrived in this country (ProMéxico, 2013). Since then, Mexico has introduced actions and strategies to help it succeed, such as supporting the relations between OEMs and indigenous firms, creating public research centers, promoting production and coproduction agreements, establishing joint ventures and alliances, and creating links between multinational corporations and small- and medium-sized local enterprises (Flores and Villareal, 2017). Accordingly, Mexico has become one of the most important global centers for assembling aircraft parts and a key investment location in the aerospace industry (FAI, 2014; Flores and Villareal, 2017).

The literature on the aerospace industry in Mexico is limited. To our knowledge, no analysis of Mexico's aerospace industry has been conducted from a QCA perspective, although Solleiro et al. (2020) examined the innovation policy supporting foreign direct investment, firms' certification in production processes, and human resources training. Hernández and Carrillo (2018) showed that the aerospace industry in Mexico has been enhanced mainly by foreign companies contributing to the development of capabilities and certifications, whereas Muñoz et al. (2019) analyzed the structure of the aerospace industry, focusing on its stakeholders and their interrelationships.

From a different perspective, Flores et al. (2017) analyzed the spatial patterns of colocated firms and establishments in Mexico's aerospace industry. In their paper, Gomis and Carrillo (2016) investigated multinational aerospace firms' productive and organizational capabilities in the global value chain, while Luna et al. (2017) assessed the aerospace manufacturing industry in Mexico from a Porter's cluster perspective.

Finally, from an econometric perspective, Chamonica and Gómez (2017) developed a panel data model, highlighting the positive influence of R\&D and foreign direct investment on technology transfer in Mexico's aerospace industry. Sandoval et al. (2019) applied graph theory to define the scope of Mexico's aerospace industry in the global value chain, while 
Villarreal et al. (2016) applied quotient placement statistics to detect spatial placement patterns in agglomerations in this industry.

\section{Methods}

\subsection{The QCA Approach}

The QCA approach tests hypotheses based on Boolean algebra and set-theoretic relations, focusing on determining sufficient and necessary conditions for yielding a desired outcome (Ragin, 2008; Wagemann, 2012). Causal complexity is a core feature of settheoretic analysis guided by three principles (Parente and Federo, 2019; Mello, 2021): conjunction, equifinality, and asymmetry. Conjunctural causation considers that a single condition is frequently insufficient and must be combined with another to achieve the desired outcome. Equifinality considers more than one sufficient (but not necessary) condition producing an outcome. Asymmetric causation means that knowing the causes of an outcome does not necessarily imply that the opposite outcome is equally known (Braumoeller, 2003; Morlino, 2005; Wagemann, 2012).

The QCA approach uses two parameters to measure the necessary and sufficient conditions for achieving a desired outcome (Roig-Tierno et al., 2017; Parente and Federo, 2019; Mello, 2021): consistency and coverage. Consistency measures the extent to which the terms of a solution are a subset of the result (i.e., a measure of fit among different conditions comprising a configuration yielding an outcome), and coverage indicates the proportion of cases that take a particular path to obtain a specific outcome (i.e., the empirical relevance of the configuration; Ragin, 2008; Parente and Federo, 2019; Mello, 2021).

Some variants of QCA methods are crisp-set QCA (csQCA), fsQCA, and multi-value QCA (mvQCA; Ragin, 2008). This research adopted the fsQCA approach as a research method to examine various membership set levels: a score of 1 indicated total membership, a score closes to 1 ( 0.8 or 0.9$)$ indicated partial membership, a score below 0.5 but above $0(0.2$ or 0.3 ) indicated further out than inside the set, and a score of 0 indicated total exclusion (Ragin, 2009). Overall, fsQCA is adequate for describing conditions because it allows the results to be examined according to partial degrees of membership rather than total membership in a specific set (Ragin, 2008).

\section{2. fsQCA and Hypothesis}

The QCA approach allows for the representation of a firm's performance using certain conditions in various configurations (Ragin, 2008; 2009), thus revealing the presence (or absence) of conditions that generate a desired outcome. Each configuration has a causally complex structure since the conditions underpinning it cannot be exhaustively examined due to the complex circumstances involved in their origin (Wagemann, 2012). This approach was appropriate for understanding the causal complexity characterizing DEFs' operations in Mexico's aerospace industry.

Typically, fsQCA research is developed in four steps (Ragin, 2008; Fiss, 2011), which this research followed: First, conventional scale measures were transformed into fuzzy membership (i.e., calibration). Second, a truth table was developed to visualize all logically possible configurations. Third, cases with desired outcomes were identified (i.e., consistency analysis). Finally, causal configurations were minimized using computed solutions and model analysis.

Computed solutions may be complex, parsimonious, or intermediate. Intermediate solutions are suitable for interpreting results (Ragin, 2008), but the configurations of complex solutions are more significant than those of parsimonious solutions, and the 
configurations of intermediate solutions provide no logical reminder or patterns of combinations of conditions not observed empirically in counterfactual analysis (Ragin, 2008; Rihoux and Ragin, 2009; Schneider and Wagemann, 2010). The hypothesis guiding this research was as follows:

$A C, I C, E C, S H R$, and $R \& D$ activities are necessary and sufficient conditions for DEFs to achieve HPLs in Mexico's aerospace industry.

\subsection{Cases and Data Collection}

Cases and conditions are crucial for a set-theoretic comparative analysis (Ragin, 2009). The cases must have a certain degree of heterogeneity to facilitate a comparison of their characteristics and define the expected result. Cases must also be sufficiently parallel to allow comparisons between specific dimensions that share similar background characteristics. In short, selected cases must present both success and failure characteristics. In this research, 17 DEFs met the validity criterion for choosing cases, which is based on firm's annual sales identifying successful and unsuccessful cases according to the methodology applied.

Two instruments were used to collect data and information in this research: a survey and semi-structured interviews. The survey and interviews were conducted from AprilMay 2018 across 17 out of 40 DEFs operating in Mexico's aerospace industry. The questionnaire and interviews enquired about $R \& D$, entrepreneurial, and innovation activities, selected AC, and SHR. When the data were collected, the model was computed according to the set-theoretic relations defined in the hypothesis using COMPASS 3.0 software.

\section{Results and Discussion}

\subsection{Sufficiency and Necessity Analysis}

A direct method was applied to calibrate the data in this research (Ragin, 2008). The five condition thresholds were 0 (total exclusion), 2 (point of indifference), and 4 (total membership), while the desired outcome thresholds were 20 (total exclusion), 500 (point of indifference), and 1,000 (full membership). The DEFs' average annual sales were used as the criterion for establishing the desired outcome (i.e., an HPL). Table 1 shows the membership values of the data in this model.

Table 1 Membership values of fuzzy sets

\begin{tabular}{cccccc}
\hline AC & IC & EC & SHR & R\&D & HPL \\
\hline 0.92 & 0.92 & 0.95 & 0.82 & 0.92 & 0.97 \\
0.92 & 0.86 & 0.92 & 0.95 & 0.82 & 0.96 \\
0.71 & 0.65 & 0.82 & 0.82 & 0.89 & 0.94 \\
0.57 & 0.86 & 0.86 & 0.77 & 0.77 & 0.85 \\
0.54 & 0.82 & 0.77 & 0.82 & 0.86 & 0.84 \\
0.90 & 0.57 & 0.86 & 0.82 & 0.94 & 0.82 \\
0.57 & 0.89 & 0.86 & 0.77 & 0.65 & 0.81 \\
0.43 & 0.92 & 0.82 & 0.94 & 0.35 & 0.5 \\
0.43 & 0.82 & 0.88 & 0.89 & 0.92 & 0.43 \\
0.43 & 0.86 & 0.86 & 0.82 & 0.71 & 0.34 \\
0.57 & 0.77 & 0.88 & 0.86 & 0.35 & 0.24 \\
0.43 & 0.71 & 0.57 & 0.43 & 0.65 & 0.16 \\
0.57 & 0.29 & 0.03 & 0.65 & 0.03 & 0.09 \\
0.23 & 0.54 & 0.08 & 0.14 & 0.54 & 0.06 \\
0.57 & 0.18 & 0.03 & 0.65 & 0.03 & 0.05 \\
0.18 & 0.18 & 0.57 & 0.57 & 0.03 & 0.05 \\
0.14 & 0.57 & 0.05 & 0.54 & 0.05 & 0.05 \\
\hline
\end{tabular}


Table 2 (i.e., the truth table) shows the configurations that might explain an HPL. Consistency analysis determines which configurations are consistent with the desired outcome (Ragin, 2008). Values below 0.80 in the RAW Consistency column indicated substantial inconsistency; hence, the first four configurations were considered sufficient for achieving an HPL. The complex solution did not consider the logical residuals, the intermediate solution considered only the empirically possible logical residuals, and the parsimonious solution considered any logical residual that contributed to generating the desired result (Ragin, 2008). However, parsimonious and intermediate solutions were also considered to identify central and peripheral causal conditions (Fiss, 2011). Notably, the parsimonious and intermediate solutions were used to explain the high performance values in this research.

Table 2 Estimated truth table

\begin{tabular}{|c|c|c|c|c|c|c|c|c|c|}
\hline$A C$ & IC & EC & SHR & $\mathrm{R} \& \mathrm{D}$ & Cases & HPL & $\begin{array}{c}\text { RAW } \\
\text { Consistency }\end{array}$ & $\begin{array}{c}\text { PRI } \\
\text { Consistency }\end{array}$ & $\begin{array}{c}\text { SYM } \\
\text { Consistency }\end{array}$ \\
\hline 1 & 1 & 1 & 1 & 1 & 7 & 1 & 0.927407 & 0.883886 & 0.883886 \\
\hline 0 & 1 & 1 & 1 & 1 & 2 & 1 & 0.823394 & 0.596859 & 0.596859 \\
\hline 0 & 1 & 1 & 0 & 1 & 1 & 1 & 0.815451 & 0.426667 & 0.426667 \\
\hline 0 & 1 & 1 & 1 & 0 & 1 & 1 & 0.808917 & 0.387755 & 0.387755 \\
\hline 1 & 1 & 1 & 1 & 0 & 1 & 0 & 0.793210 & 0.417391 & 0.417391 \\
\hline 0 & 0 & 1 & 1 & 0 & 1 & 0 & 0.708696 & 0.172840 & 0.172840 \\
\hline 0 & 1 & 0 & 0 & 1 & 1 & 0 & 0.684874 & 0.184783 & 0.184783 \\
\hline 0 & 1 & 0 & 1 & 0 & 1 & 0 & 0.582192 & 0.0827067 & 0.0827067 \\
\hline 1 & 0 & 0 & 1 & 0 & 2 & 0 & 0.523333 & 0.0714285 & 0.0714285 \\
\hline
\end{tabular}

Table 3 summarizes two of the three solutions typically computed in fsQCA models. However, parsimonious and intermediate solutions are critical to analyze the results. The parsimonious solution had a consistency value of 0.7997 and a coverage value of 0.9203 , while the intermediate solution had a consistency value of 0.8167 and a coverage value of 0.9203.

Table 3 Sufficiency analysis

\begin{tabular}{cccc}
\hline & Parsimonious Solution & & \\
\hline Causal Configuration & Raw Coverage & Unique Coverage & Consistency \\
\hline$\sim$ AC* IC*EC & 0.460784 & 0.0208334 & 0.759596 \\
AC*R\&D & 0.817402 & 0 & 0.902571 \\
EC*R\&D & 0.893382 & 0 & 0.838895 \\
SHR*R\&D & 0.887255 & 0.00612748 & 0.848769 \\
Solution coverage, 0.920343; solution consistency, 0.799787. & & \\
\hline \multicolumn{4}{c}{ Intermediate Solution } \\
\hline Causal Configuration & Row Coverage & Unique Coverage & Consistency \\
\hline IC* EC*R\&D & 0.841912 & 0.401961 & 0.840881 \\
AC* IC* EC*SHR & 0.460784 & 0.0208333 & 0.781705 \\
\hline
\end{tabular}

Four configurations were present in the parsimonious solution that explained how DEFs in Mexico's aerospace industry could achieve HPLs. Configuration 1 showed that, even in the absence of AC, the joint presence of IC and EC were sufficient conditions for DEFs to achieve the desired outcome:

$$
\sim \mathrm{AC} * \mathrm{IC} * \mathrm{EC} \rightarrow \mathrm{HPL}
$$

Configuration 2 showed that AC and R\&D activities, if jointly present, were sufficient conditions for DEFs in Mexico's aerospace industry to achieve HPLs:

$$
\mathrm{AC} * \mathrm{R} \& \mathrm{D} \rightarrow \mathrm{HPL}
$$


Configuration 3 indicated that EC and R\&D activities, if jointly present, were sufficient conditions for DEFs in Mexico's aerospace industry to achieve HPLs. Notably, Configuration 3 had the highest coverage value $(0.8933)$ with acceptable consistency $(0.8388$; see Table 3):

$$
\mathrm{EC} * \mathrm{R} \& \mathrm{D} \rightarrow \mathrm{HPL}
$$

Finally, Configuration 4 showed that SHR and R\&D activities, if jointly present, led to DEFs achieving HPLs in Mexico's aerospace industry:

$$
\mathrm{SHR}^{*} \mathrm{R} \& \mathrm{D} \rightarrow \mathrm{HPL}
$$

Nevertheless, the intermediate solution indicated that two other configurations could enable DEFs in Mexico's aerospace industry to achieve HPLs. Configuration 5, for example, showed that IC, EC, and R\&D activities, if jointly present, were sufficient conditions for achieving an HPL. Indeed, this configuration characterized a significant number of cases (84.19\%), which might explain this result, since the configuration considers a result subset consistency of 0.8408 (Table 3):

$$
\mathrm{IC} * \mathrm{EC} * \mathrm{R} \& \mathrm{D} \rightarrow \mathrm{HPL}
$$

Configuration 6 showed that, even if $\mathrm{AC}$ was absent $(\sim \mathrm{AC})$, the expected result could be achieved when IC, EC, and SHR were jointly present:

$$
\sim \text { AC * } \text { IC * EC * SHR } \rightarrow \text { HPL }
$$

The results for the parsimonious and intermediate solutions implied that several configurations would allow leading firms to achieve an HPL, as the equifinality principle suggests. Finally, the necessity analysis presented in Table 4 determined the necessary conditions, producing consistency and coverage scores for individual and specified substitutable conditions. Consistency indicates the degree to which the causal condition supersets the result, while coverage indicates the empirical relevance of a consistent superset (Ragin et al., 2007); thus, the minimum consistency value of 0.80 revealed that all conditions were necessary for DEFs in Mexico's aerospace industry to achieve HPLs.

Table 4 Analysis of necessity

\begin{tabular}{ccc}
\hline Condition Tested & Consistency & Coverage \\
\hline AC & 0.851716 & 0.762898 \\
IC & 0.912990 & 0.652936 \\
EC & 0.959559 & 0.724329 \\
R\&D & 0.910539 & 0.781283 \\
SHR & 0.948529 & 0.631321 \\
\hline
\end{tabular}

The parsimonious and intermediate solutions explained how the central and peripheral conditions could contribute to achieving the desired outcome. Central conditions indicated a strong relationship with the outcome, while peripheral conditions indicated only a causal or weak relationship (Fiss, 2011); for example, the intermediate solution had a configuration with EC as a central condition and AC, IC, and SHR as peripheral conditions.

These results suggest that DEFs should constantly develop projects by investing in R\&D to outperform their competitors in the aerospace market. Furthermore, these companies should collaborate with universities, research centers, and other stakeholders to continuously develop innovation. Interestingly, the consolidation of high-tech industries in several emerging economies can be explained by significant government intervention (Flores and Villareal, 2017). In Mexico's aerospace industry, adequate science, technology, and innovation policies must be implemented to support DEFs (e.g., by providing financial 
incentives to stimulate innovation, the development of human resources, and the design and development of education and training programs involving firms and universities, among others).

Mexico has strengthened its aerospace industry by developing and promoting $R \& D$ activities and identifying and exploiting business opportunities. However, economic incentives, training, knowledge exchanges with universities and research centers, and the development of an entrepreneurial culture should be at the core of support policies for DEFs.

In emerging economies, the consolidation of high-tech industries depends largely on government policies targeting science, technology, innovation, industry, higher education, and trade (Vertesy, 2012; Flores and Villareal, 2017). Consequently, DEFs in Mexico's aerospace industry should invest in R\&D to survive and be successful in the global market. However, according to data provided by our interviewees, despite Mexico being strengthened by policies promoting R\&D and the detection and exploitation of business opportunities, these companies typically invest in R\&D activities no more than $3 \%$ of their profits. Although this percentage is small, the strategy has positively influenced patenting activity in this industry, thus generating intellectual property relating to the design and manufacture of aircraft interiors, software for real-time assistance with aircraft operational problems, advanced manufacturing technology, computer simulation, treatment processes, and metal alloys. Patents in Mexico's aerospace industry have supported Mexican companies' science and technology development. Indeed, since R\&D is an essential condition for developing companies in this industry, the government should introduce policies that stimulate the creation of new companies and support research projects to improve firms' performance through collaboration with universities and research centers. The creation of new companies, supported by financial incentives, has been a viable path for promoting the development of the aerospace industry. Also, the government should implement education and training programs to develop qualified human resources, thus contributing to the development of innovative projects and products (Boselie et al., 2005; Berawi, 2018; Hanid et al., 2019). In the case of Mexico, the interviewees recognized the need for economic incentives, training for employees, and knowledge exchanges with universities to promote an entrepreneurship culture suitable for developing new technologies.

\section{Conclusions}

Highly innovative industries require resources to innovate and constantly outperform their competitors, and DEFs in Mexico's aerospace industry likewise require continual innovation. In this research, AC, IC, EC, SHR, and R\&D activities were all necessary conditions for achieving HPLs; however, they did not necessarily have to be present simultaneously to achieve the desired outcome. The causal complexity principle explains that DEFs in this industry may develop a sustained competitive advantage. The conditions evaluated in this study may explain the performance of firms in other countries resembling Mexico, but they may differ from the conditions in industrialized countries with different characteristics for highly innovative industries.

Nevertheless, the parsimonious and intermediate solutions suggest that R\&D activities and EC are central conditions, while AC, IC, and SHR are peripheral conditions. The analysis of central and peripheral conditions allows conclusions to be drawn regarding the causal essentiality of specific combinations of causal conditions. Central conditions are critical to the survival of DEFs in Mexico's aerospace industry, and the causal complexity in this analysis revealed how DEFs can develop a sustained competitive advantage in the global 
aerospace industry. The results indicate that R\&D activities and EC are central conditions in this process, and DEFs must constantly invest in R\&D efforts to promote innovation and improve AC. Certainly, R\&D activities and SHR are critical for exploiting profitable projects in Mexico's aerospace industry.

Finally, further research should consider other causal conditions in the analysis of HPLs, such as the financial strategies of DEFs in Mexico's aerospace industry that support innovation development. Indeed, the aerospace industry is high risk, requiring firms to carefully manage their financial conditions.

\section{References}

Barca, M., 2017. Economic Foundations of Strategic Management. Routledge, New York, New York, USA

Barney, J.B., Clark, D.N., 2007. Resource-Based Theory: Creating and Sustaining Competitive Advantage. Oxford University Press, Oxford, UK/New York, New York, USA

Bédier, C., Vancauwenberghe, M., van Sintern, W., 2008. The Growing Role of Emerging Markets in Aerospace. Available Online at https://www.mckinsey.com/industries/travel-logistics-and-infrastructure/ourinsights/the-growing-role-of-emerging-markets-in-aerospace, Accessed on January 18,2019

Berawi, M.A., 2018. The Fourth Industrial Revolution: Managing Technology Development for Competitiveness. International Journal of Technology, Volume 9(1), pp. 1-4

Boselie, P., Dietz, G., Boon, C., 2005. Commonalities and Contradictions in HRM and Performance Research. Human Resource Management Journal, Volume 15(3), pp. 6794

Braumoeller, B.F., 2003. Causal Complexity and the Study of Politics. Political Analysis, Volume 11(3), pp. 209-233

Casalet, M., 2013. Actores y Redes Públicas y Privadas en el Desarrollo del Sector Aeroespacial Internacional y Nacional: El Clúster de Querétaro, una Oportunidad Regional (Actors and Public and Private Networks in the Development of the International and National Aerospace Sector: The Querétaro Cluster, a Regional Opportunity). In: La Industria Aeroespacial: Complejidad Productiva e Institucional (The Aerospace Industry: Productive and Institutional Complexity). Casalet, M. (ed.), FLACSO, Mexico City, Mexico

Chamonica, D.D., Gómez, M., 2017. Desarrollo Tecnológico del Sector Aeronáutico en México, Canadá y EE. UU. a Partir de la I+D e IED, 2005-2015 (Technological Development of the Aeronautical Sector in Mexico, Canada and the US based on R\&D and FDI, 2005-2015). CIMEXUS, Volume 12(1), pp. 13-33

Cohen, W.M., Levinthal, D.A., 1989. Innovation and Learning: The Two Faces of R\&D. The Economic Journal, Volume 99(397), pp. 569-596

Cohen, W.M., Levinthal, D.A., 1990. Absorptive Capacity: A New Perspective on Learning and Innovation. Administrative Science Quarterly, Volume 35(1), pp. 128-152

Deloitte, 2019. Global Aerospace and Defense Industry Outlook. Available Online at https://www2.deloitte.com/content/dam/Deloitte/sg/Documents/manufacturing/s eamanufacturing-2019-global-a-and-d-sector-outlook.pdf, Accessed on January 11, 2019

FAI, 2014. Aerospace Industry in Mexico. Federación Aeronáutica Internacional. Available Online at https://docs.google.com/viewer?url=http://fai.com.mx/publicationaerospaceindustry-mexico-FAI\%20(1).pdf, Accessed on December 29, 2019

FEMIA, 2015. Overviews of Mexico's Aerospace Industry. Federación Mexicana de la 
Industria Aeroespacial. Available Online at https://www.pwc.com/mx/es/knowledgecenter/archivo/20150604-gx-publicationaerospace-industry.pdf

Fiss, P.C., 2011. Building Better Causal Theories: A Fuzzy Set Approach to Typologies in Organization Research. Academy of Management Journal, Volume 54(2), pp. 393-420

Flores, S., Villareal, A., 2017. Comparative Analysis of the Developmental Strategy of Aerospace Industry in Brazil, Canada, and Mexico: Public-Policy Implications. Latin American Policy, Volume 8(1), pp. 41-62

Flores, M., Villarreal, A., Flores, S., 2017. Spatial Co-location Patterns of Aerospace Industry Firms in Mexico. Applied Spatial Analysis and Policy, Volume 10(2), pp. 233-251

Fosfuri, A., Tribó, J.A., 2008. Exploring the Antecedents of Potential Absorptive Capacity and Its Impact on Innovation Performance. Omega, Volume 36(2), pp. 173-187

$\mathrm{Fu}, \mathrm{X}$., Pietrobelli, C., Soete, L., 2011. The Role of Foreign Technology and Indigenous Innovation in Emerging Economies: Technological Change and Catching Up. World Development, Volume 39(7), pp. 1204-1212

Gerrits, L., Pagliarin, S., 2020. Social and Causal Complexity in Qualitative Comparative Analysis (QCA): Strategies to Account for Emergence. International Journal of Social Research Methodology, Volume 24(4), pp. 501-514

Goldstein, A., 2002. The Political Economy of High-Tech Industries in Developing Countries: Aerospace in Brazil, Indonesia and South Africa. Cambridge Journal of Economics, Volume 26(4), pp. 521-538

Goldstein, A., 2006. The Political Economy of Industrial Policy in China: The Case of Aircraft Manufacturing. Journal of Chinese Economic and Business Studies, Volume 4(3), pp. 259273

Gomis, R., Carrillo, J., 2016. The Role of Multinational Enterprises in the Aerospace Industry Clusters in Mexico: The Case of Baja California. Competition \& Change, Volume 20(5), pp. 337-352

Hanid, M., Mohamed, O., Othman, M., Danuri, M.S.M., Mei Ye, K., Berawi, M.A., 2019. Critical Success Sectors (CSFS) in University-Industry Collaboration (UIC) Projects in Research Universities. International Journal of Technology, Volume 10(4), pp. 667-676

Hernández, J., Carrillo, J., 2018. Possibilities of Mexican SMEs Insertion in the Aerospace Industry Value Chain: The Baja California Case. Estudios Fronterizos (Border Studies), Volume 19, pp. 1-19

Heru, S., 2016. Innovation Capability of SMEs through Entrepreneurship, Marketing Capability, Relational Capital and Empowerment. Asia Pacific Management Review, Volume 21(4), pp. 196-203

Koroleva, E., Baggieri, M., Nalwanga, S., 2020. Company Performance: Are Environmental, Social, and Governance Factors Important? International Journal of Technology, Volume 11(8), pp. 1468-1477

Luna, J., Addepalli, S., Salonitis, K., Makatsoris, H., 2018. Assessment of an Emerging Aerospace Manufacturing Cluster and Its Dependence on the Mature Global Clusters. Procedia Manufacturing, Volume 19, pp. 26-33

Mello, P.A., 2021. Qualitative Comparative Analysis: An Introduction to Research Design and Application. Georgetown University Press, Washington, District of Columbia, USA

Moon, C.W., 1999. Impact of Organizational Learning Contexts on Choice of Governance Mode for International Strategic Combinations. Journal of High Technology Management Research, Volume 10(1), pp. 167-202

Morlino, L., 2005. Introduzione alla Ricerca Comparata (Introduction to Comparative Research). Il Mulino, Bologna, Italy

Muñoz, C., Soto, M.C. Rocha, L., 2019. Aerospace Industry in Queretaro, Mexico: A 
Perspective of Regional Innovation System. In: Proceedings of the International Conference on Industrial Engineering and Operations Management, Bangkok, Thailand, March 5-7, 2019, Code 141008

Newbert, S.L., 2007. Empirical Research on the Resource-based View of the Firm: An Assessment and Suggestions for the Future Research. Strategic Management Journal, Volume 28(2), pp. 121-146

Parente, T.C., Federo, R., 2019. Qualitative Comparative Analysis: Justifying a Neoconfigurational Approach in Managing Research. RAUSP Management Journal, Volume 54(4), pp. 399-412

ProMéxico, 2013. ProMéxico Negocios. Gobierno de México. Available Online at http://www.promexico.mx/documentos/revistanegocios/pdf/may-2013.pdf, Accessed on September 11, 2018

ProMéxico, 2016. Global Business Report. Gobierno de México. Available Online at https://www.gbreports.com/publication/mexico-aerospace-2016, Accessed on January 13, 2019

Ragin, C.C., 2008. Redesigning Social Inquiry: Redesigning Social Inquiry Fuzzy Sets and Beyond. University of Chicago Press, Chicago, Illinois, USA

Ragin, C.C., 2009. Qualitative Comparative Analysis using Fuzzy Sets (fsQCA). In: Configurational Comparative Methods: Qualitative Comparative Analysis (QCA) and Related Techniques, Rihoux, B., Ragin, C.C. (eds), Sage, Los Angeles, California, USA/London, UK, pp. 87-121

Ragin, C.C., Drass, K.A., Davey, S., 2007. Fuzzy Set/Qualitative Comparative Analysis. Available Online at http://www.socsci.uci.edu/ cragin/fsQCA, Accessed on July 22, 2018

Rihoux, B., Ragin, C.C., 2009. Configurational Comparative Methods, Qualitative Comparative Analysis (QCA) and Related Techniques. Sage, Los Angeles California, USA/London, UK

Roig-Tierno, N., González-Cruz, T.F., Llopis-Martínez, J., 2017. An Overview of Qualitative Comparative Analysis: A Bibliometric Analysis. Journal of Innovation \& Knowledge, Volume 2(1), pp. 15-23

Sandoval, S., Morales, M.A., Díaz, H.E., 2019. Estrategia de Escalamiento en las Cadenas Globales de Valor: El Caso del Sector Aeroespacial en México (Scaling Strategy in Global Value Chains: The Case of the Aerospace Sector in Mexico). Entreciencias, Volume 7(20), pp. 35-52

Schneider, C.Q., Wagemann, C., 2010. Standars of Good Practice in Qualitative Comparative Analysis. Comparative Sociology, Volume 9(3), pp. 397-418

Solleiro, J.L., Mejía, A.O., Castañón, R., 2020. Mexico's Innovation Policy for Aerospace Industry. In: International Society for Professional Innovation Management (ISPIM) Virtual Conference, June 29, 2020

Vertesy, D., 2012. The Lion with Wings: Innovation System Dynamics in the Aerospace Industry of Singapore. International Journal of Technology and Globalisation, Volume 7(1-2), pp. 118-140

Villarreal, A., Flores, S.M., Flores, M.A., 2016. Patrones de Co-localización Espacial de la Industria Aeroespacial en México (Spatial Co-location Patterns of the Aerospace Industry in Mexico). Estudios Económicos (Economic Studies), Volume 31(1), pp. 169211

Wagemann, C., 2012. What's New in the Comparative Method? QCA and Fuzzy Sets Analysis. Revista Mexicana de Análisis Político y Administración Pública (Mexican Journal of Political Analysis and Public Administration), Volume 1(1), pp. 51-75 